\title{
Working
}

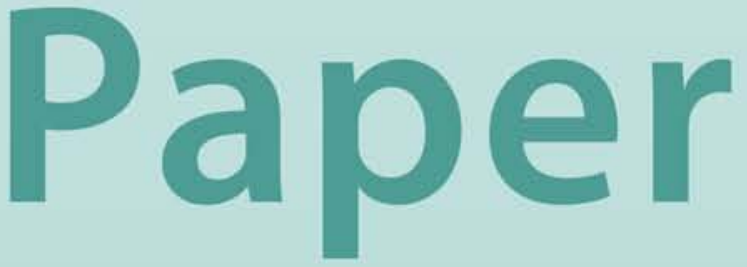




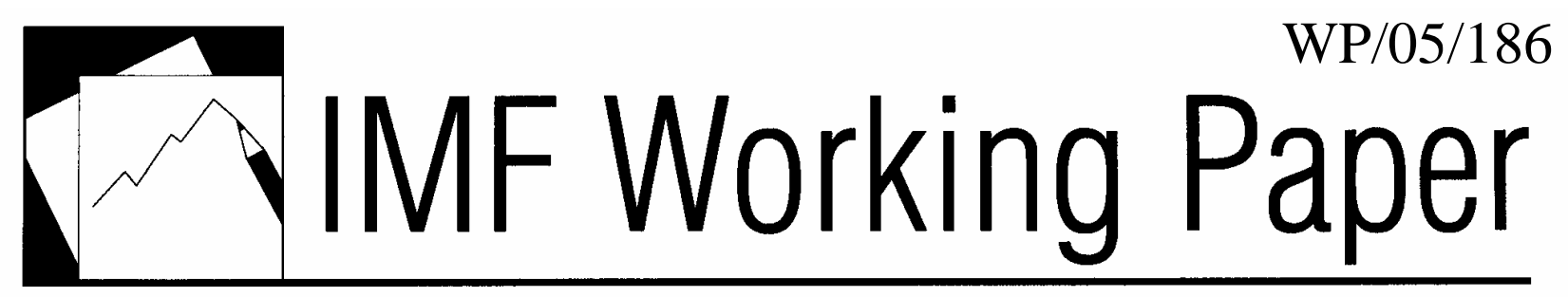

Financial Dollarization Equilibria: A Framework for Policy Analysis

Alain Ize 


\title{
IMF Working Paper
}

Monetary and Financial Systems Department

\section{Financial Dollarization Equilibria: A Framework for Policy Analysis ${ }^{1}$}

\author{
Prepared by Alain Ize
}

September 2005

\begin{abstract}
This Working Paper should not be reported as representing the views of the IMF. The views expressed in this Working Paper are those of the author(s) and do not necessarily represent those of the IMF or IMF policy. Working Papers describe research in progress by the author(s) and are published to elicit comments and to further debate.

Rapidly rising dollarization and numerous related financial crises in recent years have heightened the need for policy action. This paper contributes to the policy debate by presenting a common analytic framework that examines the roots of de facto financial dollarization under different economic environments and analyzes its interplay with monetary and prudential policies. In addition to providing a systematic analysis of the existence, stability, and multiplicity of dollarization equilibria, the paper makes a few novel contributions. In particular, it stresses the key role played by monetary policy endogeneity and identifies the underlying determinants of the peso premium that are responsible for inducing a preference for the dollar in financial transactions.

JEL Classification Numbers: E50, G11, G20
\end{abstract}

Keywords: Dollarization, Monetary policy, Credit risk

Author(s) E-Mail Address: aize@imf.org

\footnotetext{
${ }^{1}$ This paper was presented at the Conference on the Policy Implications of De Facto Dollarization held in Lima Peru during April 21-22, 2005. It benefited from comments by Adrian Armas, Olivier Jeanne, Eduardo Levy Yeyati, and Rodolfo Maino.
} 


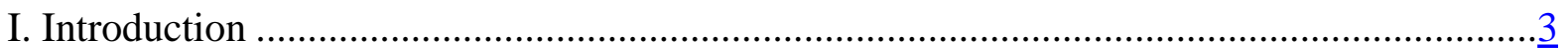

II. The Model …..................................................................................................... 4

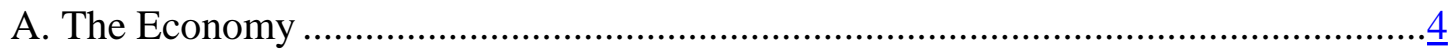

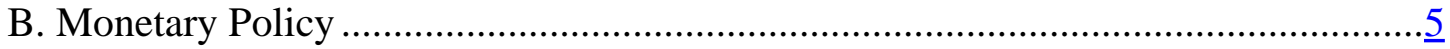

III. The Risk Aversion Paradigm ...................................................................................... 6

A. Price Risk and the Peso Premium ....................................................................

B. Minimum Variance and Safe Haven Portfolios ..................................................

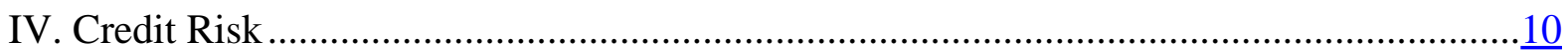

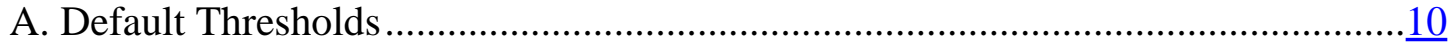

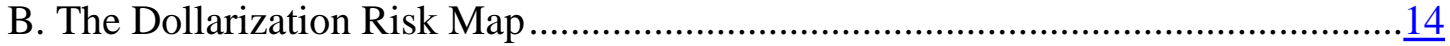

Exogenous monetary policy................................................................ 14

Endogenous monetary policy.......................................................... 15

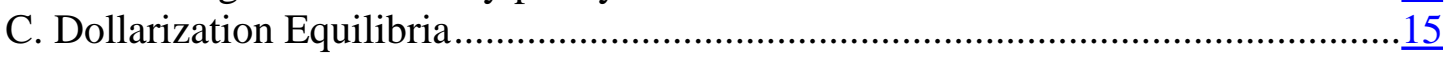

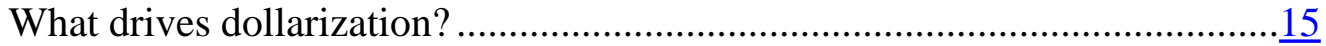

Equilibria under an exogenous monetary policy …..................................17

Equilibria under an endogenous monetary policy ...................................18

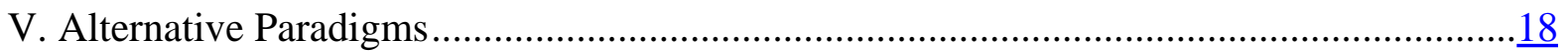

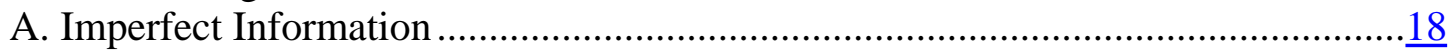

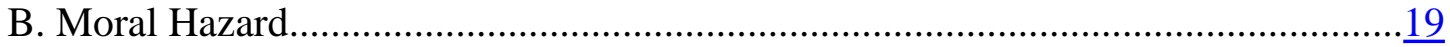

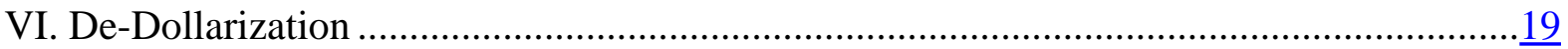

A. Strengthening Monetary Credibility ...........................................................

B. Moving Towards a More Flexible Exchange Rate Regime ................................

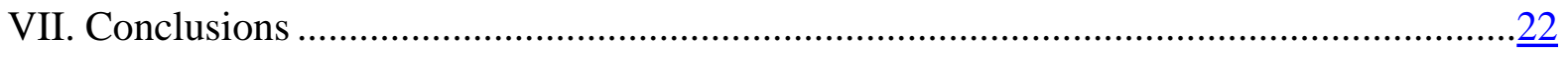

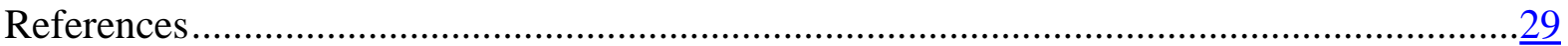

Figures

1. Interest Rates without Credit Risk .....................................................................

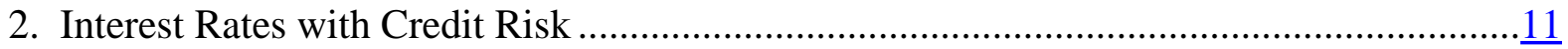

3. The Dollarization Risk Map with an Exogenous Monetary Policy …..............................13

4. The Dollarization Risk Map with an Endogenous Monetary Policy .................................16

Appendices

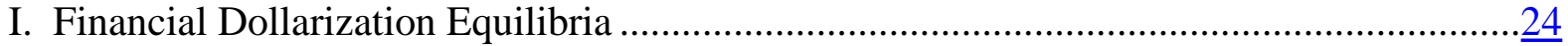

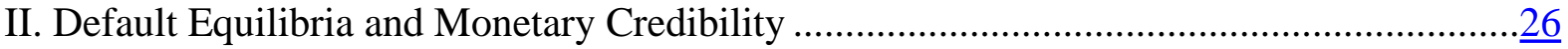

III. Moral Hazard Equilibria ................................................................................ 


\section{INTRODUCTION}

The continuing upward trend in de facto dollarization in most regions of the world and the wave of recent corporate and banking crises in Asia and Latin America, where dollarization played an important supporting role, have raised policymakers' consciousness about the need for policy action. Perceptions of de facto financial dollarization as a mostly unavoidable phenomenon, generally benign, and often beneficial to monetary stability and financial development in countries with limited currency credibility, have given way to more sobering thoughts. ${ }^{2}$ With the growing realization of the risks that dollarization imposes on the financial system, policymakers' attention has shifted towards finding ways to reverse dollarization or at least limit its drawbacks.

This paper aims at providing a unified framework for policy analysis, based on a good grasp of the roots of dollarization and its interplay with monetary and prudential policies. The paper both extends and streamlines a previous paper (Ize and Powell, 2004) that covered basic analytical issues less thoroughly but addressed policy issues in greater length, particularly on the prudential side.

The paper starts from the premise that financial dollarization is a home grown phenomenon resulting from a credit market equilibrium between creditors and borrowers who both optimize on the currency composition of loan contracts. The focus of analysis differs in this sense from that followed in the "original sin" and "liability dollarization" literature, which does not model currency choice as a market equilibrium or, when it does, stresses equilibria between domestic borrowers and foreign lenders. Instead, this paper brings together the more limited (but growing) literature that looks at asset and liability dollarization as a simultaneous and interactive phenomenon. ${ }^{3}$

In addition to providing a systematic and uniform analysis of the existence, stability, and multiplicity of dollarization equilibria under different paradigms and institutional and market environments, the paper makes a few novel contributions. In particular, the paper provides a finer analysis of the underpinnings of monetary policy endogeneity and the peso premium, both key underlying determinants of dollarization. It distinguishes four inter-related yet distinct features of monetary policy: (i) credibility; (ii) fear of floating; (iii) overvaluation overhang; and (iv) asymmetry. All four affect dollarization, but in different ways and through different channels. Thus, a sound understanding of their respective roles is important in shaping up policy reform.

\footnotetext{
${ }^{2}$ For a recent review of dollarization trends and risks, see De Nicolo, Honohan, and Ize (2005).

${ }^{3}$ Key contributions in this direction were made by Calvo and Guidotti (1989), Ize and Levy Yeyati (1998), Burnside, Eichenbaum, and Rebelo (2001), Chamon (2001), Aghion, Bacchetta, and Banerjee (2001), Jeanne (2002), and Broda and Levy Yeyati (2003).
} 
Section II presents the basic framework of analysis. Section III applies this framework to the case with risk aversion but no defaults. Section IV explores the opposite case with defaults but no risk aversion. Section $\mathrm{V}$ extends the framework to the case of imperfect information and moral hazard. Based on these alternative paradigms, Section VI examines which changes in the monetary regime might help de-dollarization. Section VII concludes by briefly reviewing alternative ways to promote de-dollarization.

\section{THE MODEL}

\section{A. The Economy}

The economy consists of: (i) a government (that includes a monetary authority and a prudential authority); (ii) investors (who may be risk averse and invest in a mix of fully guaranteed pesos and dollar deposits); (iii) risk neutral corporates (which borrow in a mix of pesos and dollars to finance projects); and (iv) risk neutral banks (which intermediate between corporate and investors while taking themselves a neutral currency position). I define $\lambda_{i}$ as the dollar share in the portfolio of the marginal lender or marginal borrower and $\lambda$ as the dollar share in the economy as a whole. An "equilibrium" currency composition is obtained when all agents transact with the same currency composition $\left(\lambda_{i}=\lambda\right.$, for all $\left.i^{\prime} s\right)$ and monetary policy is consistent with that level of dollarization.

The economy is subjected to random real or capital account disturbances that affect the equilibrium real exchange rate and may result in overvaluations or undervaluations. Reflecting asymmetric price rigidities, undervaluations are immediately resolved through price increases while overvaluations must be resolved through nominal depreciations. Yet, such overvaluations may linger on due to a reticence (explained below) by the monetary authority in devaluing the exchange rate. Thus, exchange rate overvaluations tend to build up over time until they are eventually undone through a large nominal depreciation.

I will thus assume that: (i) the equilibrium real exchange rate is zero; (ii) there is a current overvaluation overhang $\widehat{\delta}$; (iii) next period's real exchange rate may become further overvalued so that the real equilibrium exchange rate, $\delta^{*}$, is uniformly distributed over the range $[\widehat{\delta}, \widehat{\delta}+\tilde{\delta}] ;^{4}$ and iv) there is a threshold exchange rate overvaluation for which the

\footnotetext{
${ }^{4}$ In a more complete model, the range of exchange rate shocks would include values of $\delta^{*}$ below $\widehat{\delta}$ or in the negative range, reflecting the fact that the distribution of shocks should be broadly symmetric (it should also include undervaluation shocks). However, as long as the exchange rate peg is maintained under undervaluation shocks (with adjustments towards the equilibrium exchange rate taking place through price adjustments rather than nominal appreciations), the returns on all currencies would be equally affected over that range. Hence, making the distribution of shocks symmetric would complicate the model without affecting currency choice. For simplicity, I will thus exclusively focus on overvaluation shocks. Notice
} 
authorities allow the exchange rate to float so as to eliminate the overvaluation. Hence, if $\delta$ is next period's real devaluation, when $\delta^{*}>\bar{\delta}, \delta=\delta^{*}$ and the real overvaluation is eliminated; instead, when $\delta^{*}<\bar{\delta}, \delta=0$ and the real overvaluation becomes $\delta^{*}$.

Borrowers invest in a project whose real return next period, $\rho$, is expected to fall below its equilibrium level, $\hat{\rho}$, if the real exchange rate becomes overvalued, and will rise back to its equilibrium level if the exchange rate is allowed to float: ${ }^{5}$

$$
\rho=\hat{\rho}-\mu\left(\delta^{*}-\delta\right), \mu \in[0,1]
$$

Reflecting the maturity of financial transactions, financial contracts are settled before agents observe the shock. Borrowers default when the real cost of debt servicing, taking into account the equilibrium and actual exchange rate, exceeds the return on the project. In the case of default, banks receive $\rho$ minus a liquidation cost, $\omega$. Thus, by increasing project returns, devaluations are expected to be expansionary (in relation to today's equilibrium) as long as there is an overhang $(\widehat{\delta}>0)$. However, balance sheet effects can make them contractionary, as the liquidation costs associated with bankruptcies can more than offset the direct output gains of the devaluation (this will be the case when $\varpi>\mu \widehat{\delta}$ ). ${ }^{6}$

\section{B. Monetary Policy}

Monetary policy is set after the shock is observed and there is no possibility to precommit. Based on the realized shock and the welfare implications of a devaluation, the monetary authority must decide whether to continue pegging the exchange rate at its current level or to let it depreciate so as to match the equilibrium real exchange rate. The choice of the devaluation threshold, $\bar{\delta}$, is based on comparing the welfare impacts of not devaluing versus devaluing. The former includes the loss of output caused by overvaluations and the possible associated financial stress resulting from a depressed economic activity. The latter reflects the authorities' concerns about the financial stress induced by a devaluation, or the

however that the asymmetric monetary policy response to overvaluations and undervaluations is a key feature underlying the competitiveness of the dollar relative to the peso (this point is addressed later in the paper).

${ }^{5}$ The borrower can be viewed as a representative firm that exports part of its output. A devaluation (overvaluation) increases (reduces) profits because it increases (reduces) the price of the tradable share of the firm's output and, through substitution effects, increases (reduces) demand for the non tradable component.

${ }^{6}$ There is good evidence that depreciations tend to be contractionary in highly dollarized economies (see Galindo et al. 2003). 
inflationary implications of the devaluation when monetary policy lacks credibility. ${ }^{7}$

The higher the monetary credibility gap, the higher the expected inflation passthrough of a devaluation, $v$, and, hence the higher the penalty associated with a devaluation. I thus assume that the credibility cost of devaluing is proportional to the passthrough: $a v, a>0$. As for financial stress, I assume it is proportional to the cost of liquidations. Thus, a factor $b \varpi(b>0)$ also enters into the welfare function whenever there is a default.

For simplicity, I will only consider the two polar cases where: (i) monetary stability concerns fully outweigh financial stability concerns (b is small; a/b is large); or (ii) financial stability concerns fully dominate monetary stability concerns (b is small; $a / b$ is small). In the first case, the devaluation threshold is exogenous to dollarization and devaluations occur for:

$$
\delta^{*}>\bar{\delta}_{v}=\frac{a v}{\mu}
$$

In the second case, the devaluation threshold becomes a function of dollarization and there are three possibilities:

- $\quad$ when not devaluing triggers a default, the authorities will devalue as soon as needed to prevent a default;

- $\quad$ when devaluing triggers a default, the authorities will resist devaluation as much as possible to prevent a default; and

- $\quad$ when a default takes place whether the exchange rate is devalued or not, financial stress concerns cancel out and the government will devalue for $\delta^{*}>\bar{\delta}_{v}$.

\section{The Risk AVersion PARAdigm}

\section{A. Price Risk and the Peso Premium}

Consider first the case where project returns are high enough to eliminate credit risk and define $R^{*}\left(\lambda_{i}, \bar{\delta}\right)$ as the credit risk free nominal interest rate faced by a marginal creditor (borrower) in an economy with a monetary rule $\bar{\delta}$. Since borrowers are risk-neutral, interest rate parity should hold and ensure that the real credit risk-free ex-ante rate, $r^{*}$, is the same for any lending mix. Assuming perfect capital mobility and assuming away country risk, it should also ensure that the nominal credit risk-free dollar interest rate equals the U.S. dollar rate, $R_{D}^{*}$. Finally, for any lending mix, it should equalize the real ex-ante credit risk-free rate

\footnotetext{
${ }^{7}$ The perceived monetary weaknesses could in turn result from a weak fiscal environment.
} 
to the nominal rate, adjusted for expected valuation gains and losses due to inflation and depreciation:

$$
r^{*}=R^{*}\left(\lambda_{i}, \bar{\delta}\right)-\frac{1}{\tilde{\delta}}\left[\int_{\bar{\delta}}^{\hat{\delta}+\tilde{\delta}}\left[\left(1-\lambda_{i}\right) \frac{v}{1-v}-\lambda_{i}\right] \delta^{*} d \delta^{*}\right]
$$

From which:

$$
R^{*}\left(\lambda_{i}, \bar{\delta}\right)=r^{*}+\frac{v-\lambda_{i}}{1-v} \Delta
$$

where $\Delta$ is the expected depreciation:

$$
\Delta=\frac{1}{\tilde{\delta}} \int_{\bar{\delta}}^{\hat{\delta}+\tilde{\delta}} \delta^{*} d \delta^{*}
$$

It follows that:

$$
\begin{gathered}
R_{D}^{*}=R^{*}(1, \bar{\delta})=r^{*}-\Delta \\
R_{P}^{*}=R^{*}(0, \bar{\delta})=r^{*}+\frac{v}{1-v} \Delta
\end{gathered}
$$

Thus, the dollar earns a negative premium, reflecting valuation gains in the event of a nominal depreciation, while the peso earns a positive premium, reflecting valuation losses (derived from inflation) under the same event. The lower nominal cost of the dollar relative to the peso derives in part from an asymmetric monetary policy that may correct for overvaluations through nominal devaluations but never corrects for undervaluations through nominal appreciations. This ends up rewarding the dollar which becomes a one-sided bet (its value, compared to the peso, can only go up, but not down). As we will see in the next section, this is a key underlying determinant of high dollarization in an economy with credit risk. The peso is further handicapped vis-à-vis the dollar by the lack of credibility of monetary policy. The less credible monetary policy is (the higher $v$ ), the higher the peso's nominal cost, reflecting its higher exposure to inflationary losses.

\section{B. Minimum Variance and Safe Haven Portfolios}

Consider, as an alternative to the peso, a mixed currency portfolio such that $\lambda_{i}=v$. The returns of this portfolio are invariant to the devaluation outcome, as the gains on dollar assets in the event of a depreciation are exactly offset by the losses on peso assets (Figure 1 illustrates): 
Figure 1. Interest Rates without Credit Risk

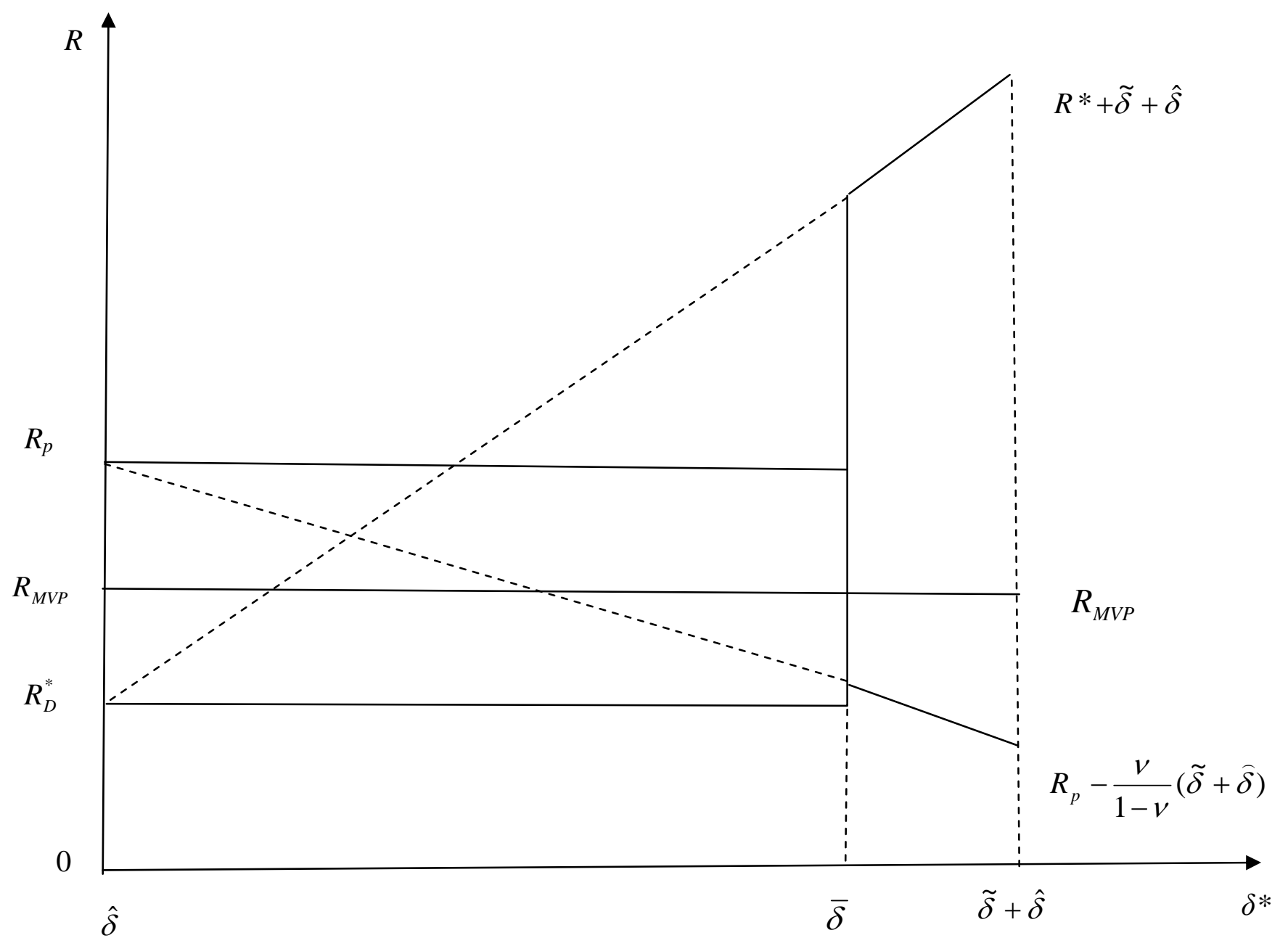




$$
R_{M V P}^{*}=R^{*}(v, \bar{\delta})=r^{*}
$$

I will call this perfectly hedged portfolio the Minimum Variance Portfolio (MVP) and refer to "MVPs" as a composite currency. For $v=0$, the MVP rate equals the peso rate. Thus, the MVP can be viewed as a perfectly credible peso surrogate that protects the investor from devaluation-induced inflationary losses. ${ }^{8}$ For borrowers, since prices rise by a factor $v$ after a depreciation, the MVP can also be viewed as the currency in which their prices are "denominated," hence the one that minimizes mismatches in their balance sheets.

In the absence of risk aversion, investors and borrowers only care about expected returns. Since the latter are equalized through interest rate parity, financial market participants are indifferent to the currency mix. However, when investors are risk averse, they should prefer the portfolio which best allows them to smooth out their income. If their financial and non financial incomes are uncorrelated, this reduces to picking the mix with the least volatile returns. The MVP mix should thus clearly dominate and dollarization should be determined by the MVP dollar share $(\lambda=v) .{ }^{9}$ Notice that dollarization does not depend on the probability of a regime change. Instead, it only depends on the expected monetary policy following a collapse of the exchange rate, no matter how improbable this collapse.

When non financial income and financial income are correlated, investors prefer a mix whose returns are higher when their non financial income is lower. In particular, should non financial income be negatively correlated with the exchange rate (devaluations coincide with output contractions), this would promote the use of the dollar as a "safe haven", beyond the MVP level. ${ }^{10}$ In this model, however, the opposite holds true in the absence of credit risk. Project returns (hence, output and income) rise with depreciations. Hence, the safe haven effect should promote the peso rather than the dollar.

\footnotetext{
${ }^{8}$ However, the MVP only protects against inflation to the extent that the expected passthrough equals the actual passthrough.

${ }^{9}$ This is the basic result in Ize and Levy Yeyati (2003). It is easy to show that MVP dollarization can be expressed as the covariance of the price level and the nominal exchange rate divided by the variance of the nominal exchange rate; or, alternatively, as the ratio of the standard deviations of the exchange rate and the price level, times their correlation (see Appendix I).
}

${ }^{10}$ See Appendix I for a formal derivation. 


\section{CREDit Risk}

\section{A. Default Thresholds}

Consider now the case of risk neutral investors, where corporates may default, but banks have sufficient capital to remain solvent under any size shock. Let $R\left(\lambda_{i}, \bar{\delta}\right)$ be the nominal lending rate associated with a mix $\lambda_{i}$ and a monetary policy $\bar{\delta}$ in the presence of credit risk. Nominal rates should rise to incorporate expected loan losses, which are a function of monetary policy, the currency mix, and the profile of project returns, all of which are endogenous. A default can occur due either to a devaluation that triggers valuation losses on a highly dollarized loan (i.e., due to currency risk) or from an overvaluation (i.e., the absence of a devaluation) that depresses the return on the project below the interest rate on the loan. In this latter case, the default occurs due to a combination of "output-induced credit risk" and "interest rate-induced credit risk."

A simple graphic analysis helps situate the problem (Figure 2). In the event of a devaluationinduced default, the return on a dollar loan, $\hat{\rho}$, is below the risk-free dollar return but above the return in the absence of a devaluation, $R_{D}$. Instead, because it does not benefit from such a windfall, the MVP rate must compensate by offering a higher return than the dollar rate under no devaluation. An MVP loan is therefore not exposed to currency risk but more “expensive," hence more exposed to interest rate-output risk in the event of no devaluation. The more sensitive project returns are to overvaluations (the higher $\mu$ ), the more scope for interest rate-output risk as project returns dip deeper below the equilibrium return. An increase in $\bar{\delta}$ has a similar effect; fear of floating (i.e., delaying needed exchange rate adjustments) reduces the scope for currency risk but increases the scope for interest rate risk. The peso is further exposed than the MVP to interest rate risk, due to the fact that its value is eroded by inflation in the event of a depreciation (hence, its nominal interest rate is higher).

Proceeding now to a formal analysis, define $\delta^{X}\left(\lambda_{i}, \bar{\delta}\right)$ and $\delta^{R}\left(\lambda_{i}, \bar{\delta}\right)$ as the exchange rate thresholds that trigger currency-induced and interest rate-induced corporate bankruptcies, respectively. Consider first the case of mixes such that $\delta^{R}\left(\lambda_{i}, \bar{\delta}\right)>\bar{\delta}$. Since a devaluation occurs before the interest rate default threshold is reached, these mixes are only exposed to currency risk, but not to interest rate risk. For the marginal borrower, $\delta^{X}$ is such that the expost real interest rate equals the rate of return on the project:

$$
R-\frac{v}{1-v}\left(1-\lambda_{i}\right) \delta^{X}+\lambda_{i} \delta^{X}=\widehat{\rho}
$$

Or: 
Figure 2. Interest Rates with Credit Risk

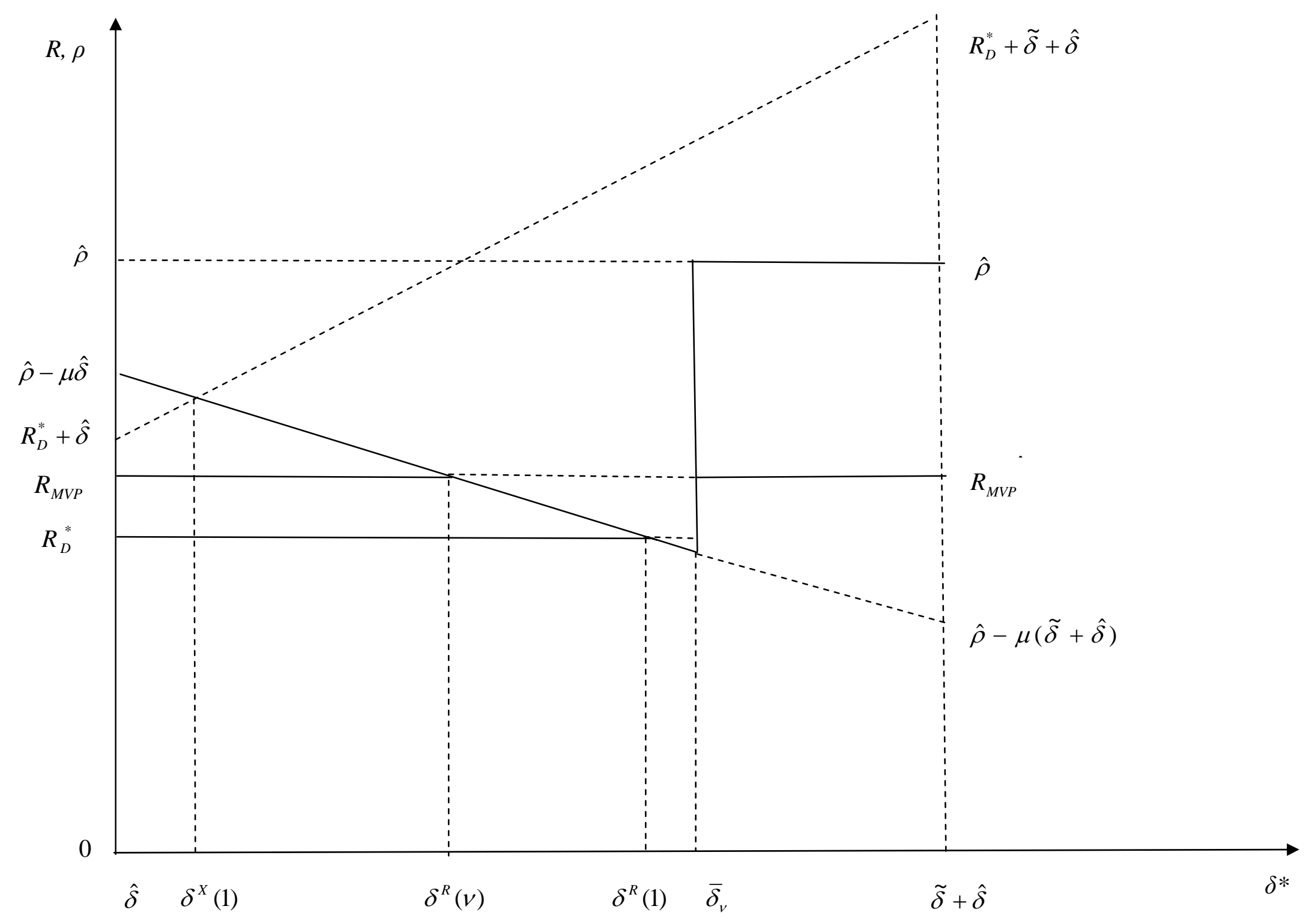




$$
\delta^{X}=\frac{1-v}{\lambda_{i}-v}[\hat{\rho}-R],
$$

where, assuming $\hat{\rho}<R+\bar{\delta}$ (the devaluation threshold is high enough to trigger a default under full dollarization), $R$ is such that:

$$
\frac{1}{\tilde{\delta}}\left[\int_{\hat{\delta}}^{\bar{\delta}} R d \delta^{*}+\int_{\bar{\delta}}^{\hat{\delta}+\tilde{\delta}}(\widehat{\rho}-\varpi) d \delta^{*}\right]=r^{*}
$$

Solving (11), using (10), leads to:

$$
\frac{\delta^{X}}{\tilde{\delta}}=\frac{1-v}{\lambda_{i}-v} \frac{1}{\bar{\delta}-\widehat{\delta}}\left(d-\frac{\tilde{\delta}-\bar{\delta}}{\hat{\delta}} \varpi\right)
$$

where $d=\hat{\rho}-\varpi-r^{*}$ is the equilibrium distance to default, inclusive of liquidation costs, which I assume to be positive. Holding $\bar{\delta}$ constant (i.e., for a given monetary policy), the $\delta^{X}$ schedule has the hyperbolic shape with respect to $\lambda_{i}$ shown in Figure 3. Currency-induced credit risk, $\tilde{\delta}+\widehat{\delta}-\delta^{X}$, rises with dollarization and vanishes below MVP. ${ }^{11}$

Take now the case of mixes $\lambda_{i} \leq v$, that are only exposed to interest/output rate risk. The exchange rate shock $\delta^{R}$ that triggers a default when the exchange rate is not devalued is such that:

$$
\delta^{R}=\frac{\hat{\rho}-R}{\mu},
$$

where $R$ is given by:

$$
\frac{1}{\tilde{\delta}}\left[\int_{\hat{\delta}}^{\delta^{R}} R d \delta^{*}+\int_{\delta^{R}}^{\bar{\delta}}\left(\hat{\rho}-\mu \delta^{*}-\varpi\right) d \delta^{*}+\int_{\bar{\delta}}^{\hat{\delta}+\tilde{\delta}}\left(R+\frac{\lambda_{i}-v}{1-\nu} \delta^{*}\right) d \delta^{*}\right]=r^{*}
$$

\footnotetext{
${ }^{11}$ For $\delta^{X}<\bar{\delta}$, the $\delta^{X}$ schedule is "notional." It determines the exchange rate that would trigger a default in the absence of fear of floating.
} 
Figure 3. The Dollarization Risk Map with an Exogenous Monetary Policy

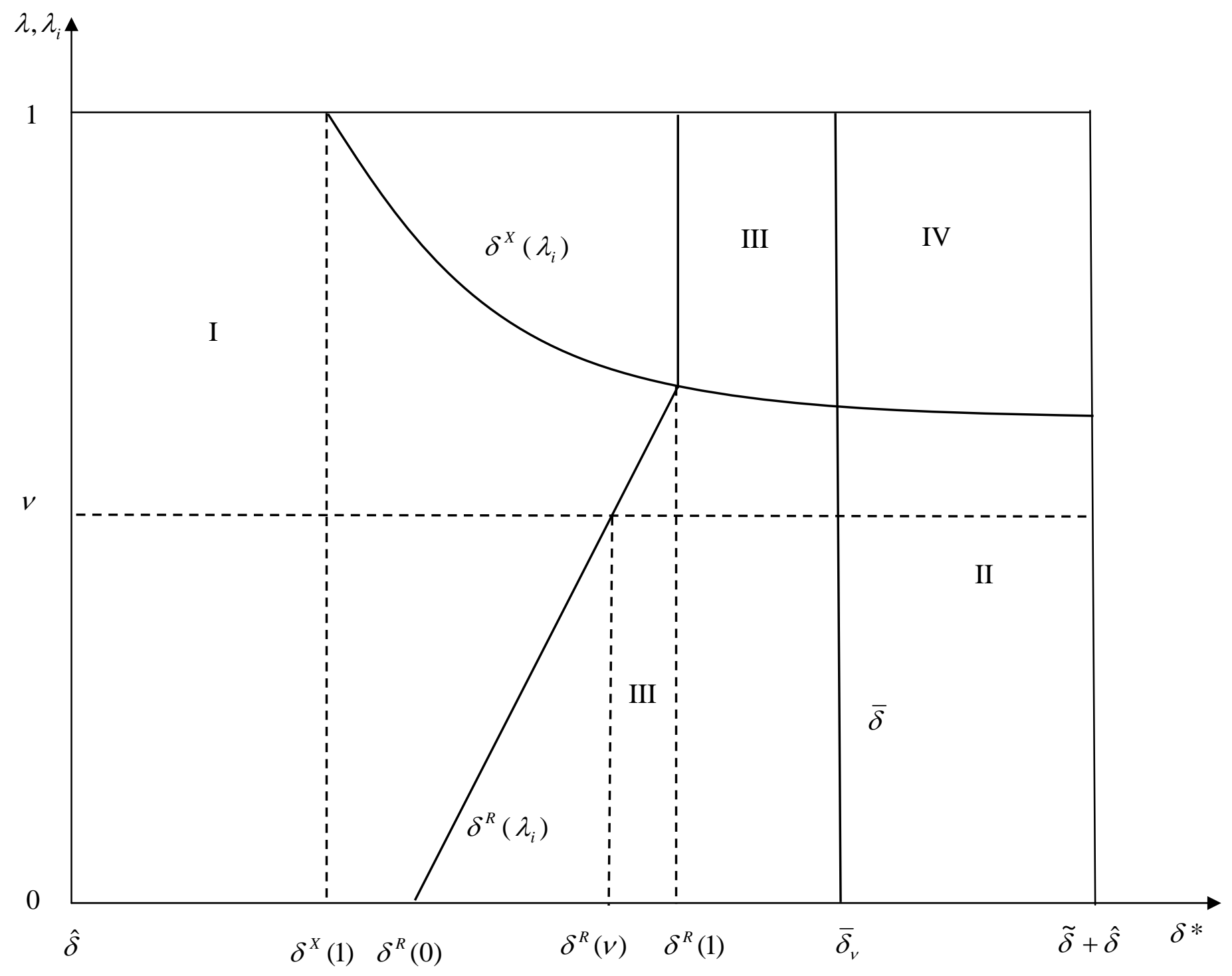


Solving (14) using (13) leads to:

$$
\left(\delta^{R} / \tilde{\delta}-\bar{\delta} / \tilde{\delta}\right)^{2}+2 \delta^{R} / \tilde{\delta}+2(\varpi / \mu \tilde{\delta})\left(1+\delta^{R} / \tilde{\delta}-\bar{\delta} / \tilde{\delta}\right)=\frac{2}{\mu \tilde{\delta}}\left(d+\frac{\lambda_{i}-v}{1-v} \Delta\right)
$$

It can be easily checked that $\frac{d \delta^{R}}{d \lambda_{i}}>0$ for $\mu, \Delta>0$. Hence, the $\delta^{R}$ schedule is positively sloped (interest rate risk rises as $\lambda_{i}$ declines) if there is a positive probability of an exchange rate collapse and project returns are exchange rate sensitive.

Consider finally the case of mixes exposed to both currency risk and interest rate risk, which are in the high dollarization region $\left(\lambda_{i} \in\left[\lambda^{X}, 1\right]\right.$, see Figure 2) and such that $\delta^{R}\left(\lambda_{i}, \bar{\delta}\right)<\bar{\delta}$ :

$$
\frac{1}{\tilde{\delta}}\left[\int_{\widehat{\delta}}^{\delta^{R}} R d \delta^{*}+\int_{\delta^{R}}^{\bar{\delta}}\left(\widehat{\rho}-\mu \delta^{*}-\varpi\right) d \delta^{*}+\int_{\bar{\delta}}^{\hat{\delta}+\tilde{\delta}}(\widehat{\rho}-\varpi) d \delta^{*}\right]=r^{*}
$$

Solving (16) leads to:

$$
\left(\delta^{R} / \tilde{\delta}-\widehat{\delta} / \tilde{\delta}\right)^{2}+(\bar{\delta} / \tilde{\delta})^{2}-(\widehat{\delta} / \widehat{\delta})^{2}-2(\varpi / \mu \widehat{\delta})\left(\delta^{R} / \tilde{\delta}-\widehat{\delta} / \tilde{\delta}\right)=\frac{2 d}{\mu \tilde{\delta}}
$$

Returns are the same for any mix in that range ( $R$ is independent of $\lambda_{i}$ ); hence any mix is similarly priced and the $\delta^{R}$ schedule is vertical.

\section{B. The Dollarization Risk Map}

A dollarization risk map can now be drawn as a function of the default thresholds, monetary policy, and aggregate dollarization.

\section{Exogenous monetary policy}

Consider first the simpler case in which the monetary authority is not concerned about the financial stress implications of monetary policy $(b=0)$. In this case, the $\bar{\delta}$ schedule is a vertical line that divides the risk map into four regions (Figure 3). In Region I, where shocks are moderate, nothing happens. In Region II, shocks are large and there are currency crises (the exchange rate is devalued). Yet, the financial system remains resilient because the currency mix is not too different from MVP (there is only a moderate currency mismatch). In Region III, shocks are not sufficiently large to trigger a devaluation, yet failure to devalue triggers an interest rate risk-induced debt crisis. Finally, in Region IV, shocks are large enough to trigger a devaluation and the economy sufficiently dollarized to cause currency 
risk-induced corporate bankruptcies. As a result, there is a twin currency-financial crisis.

\section{Endogenous monetary policy}

Consider next the case in which financial stability concerns dominate, so that the central bank fits its monetary policy to minimize the probability of financial crises. The devaluation trigger (and the default schedules) then becomes a function of aggregate dollarization, $\bar{\delta}(\lambda)$. Should all loans be denominated in MVPs (or pesos), the central bank would adopt a flexible exchange rate policy and devalue for all shocks that would trigger corporate defaults in the absence of devaluations. Thus, the devaluation and interest rate default triggers would coincide, $\bar{\delta}(v)=\delta^{R}(v, \bar{\delta}(v))$, and the MVP equilibrium would be risk-free. On the other hand, should all loans be dollar denominated, the central bank would resist devaluing as long as doing so would trigger currency risk-induced defaults. However, when failure to devalue triggers an interest rate risk-induced default, financial stability concerns cancel out. As a result, the devaluation trigger coincides again with the interest rate risk default trigger (see Figure 4). Thus, the endogeneity of monetary policy with respect to dollarization always eliminates interest rate risk for loans whose currency composition matches that of the economy (e.g., for $\left.\lambda_{i}=\lambda\right)^{12}$

\section{Dollarization Equilibria}

\section{What drives dollarization?}

Since monetary policy reflects aggregate dollarization, individual agents take monetary policy (hence, collective choices) as given when making their portfolio choices. An equilibrium is stable if, given the monetary policy associated with it, individual borrowers have no incentive to deviate from the currency choices made by other agents.

Proposition 1. With perfect information, no risk aversion, and sound banks, credit risk is fully internalized and banks price their loans so as to minimize expected liquidation costs, i.e., credit risk.

Proof. See Appendix I

A high dollarization mix is thus preferred to a low dollarization mix if the currency risk of the former is lower than the interest rate/output risk of the latter. I now examine under which conditions stable equilibria exist.

\footnotetext{
${ }^{12}$ This implies that the region of interest rate risk-induced crises disappears for the economy as a whole (although not for an individual borrower who borrows more in pesos than the average). This is consistent with the fact that currency-triggered financial crises seem to recur more frequently than overvaluation-induced crises.
} 
Figure 4. The Dollarization Risk Map with an Endogenous Monetary Policy

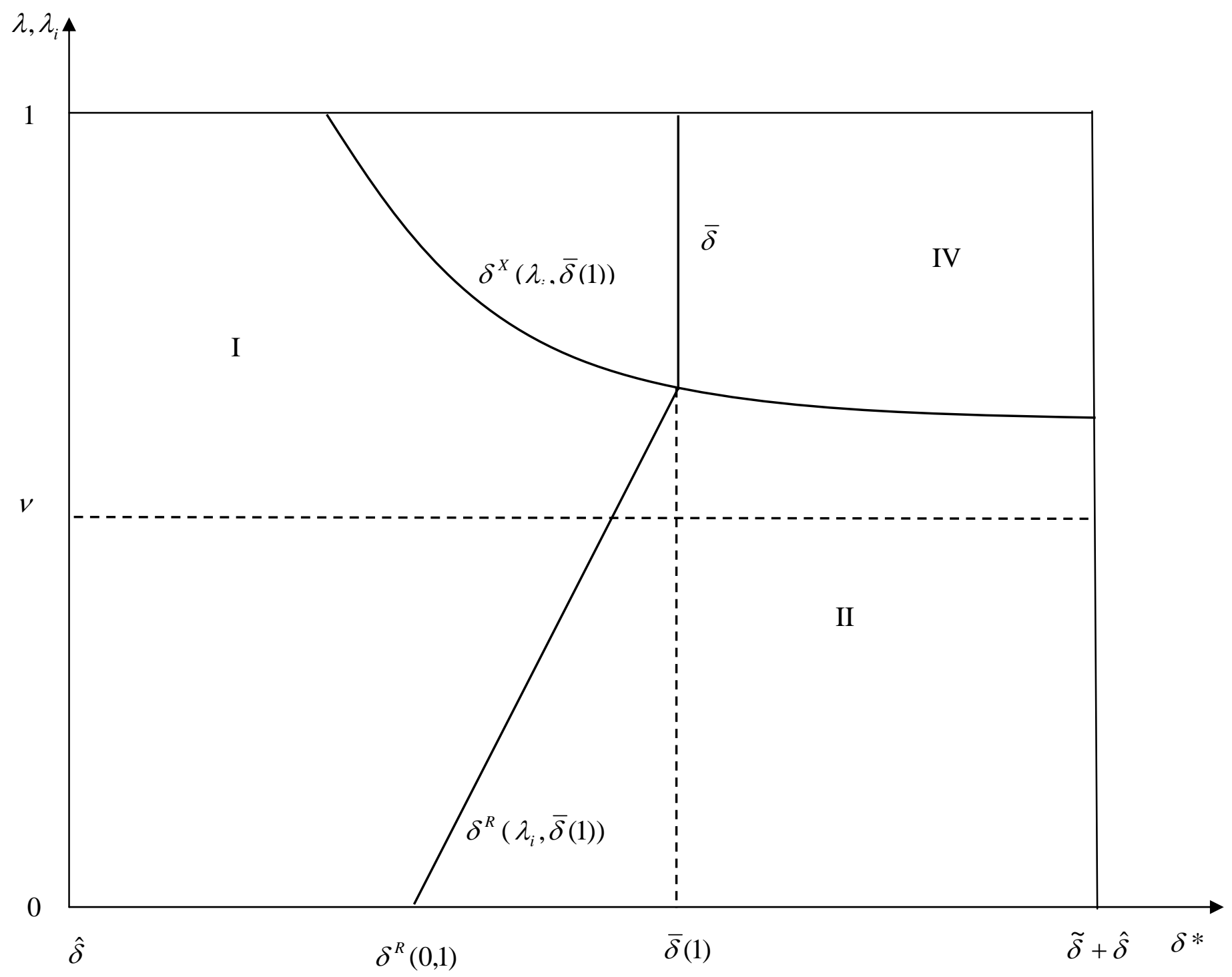




\section{Equilibria under an exogenous monetary policy}

Consider first the case $b=0$. In this case, the marginal borrower faces the same currency choices as the average borrower. The first best currency mixes (those with lowest credit risk) are therefore spontaneously chosen by all borrowers and constitute stable (although not necessarily unique) equilibria.

Proposition 2. When credibility concerns dominate and credibility is high, highly pesified equilibria are locally weakly stable (the economy could stay there but could also drift towards higher dollarization); as credibility declines, contracts dollarize, migrating towards an equilibrium with a dollar share slightly above MVP; as credibility declines further, the economy stays in the MVP region if there is no overvaluation overhang or project returns do not increase with a devaluation; however, if there is a sufficient overhang and a positive probability of an exchange rate collapse $(\widehat{\delta}>(\tilde{\delta}+\bar{\delta}-\bar{\delta}) / 2>0)$, moderate liquidation costs, and project returns increase with a devaluation $(\mu>0)$, there exists a positive range of equilibrium distances to default such that the economy eventually jumps to a highly dollarized equilibrium.

Proof. See Appendix II

The existence of an overvaluation overhang, combined with the fact that overvaluations are contractionary, makes the profile of project returns closer to that of the dollar, as illustrated by Figure 2. The higher return obtained on dollar loans in the event of a devaluation reduces their required return in the absence of a devaluation. Thus, project and dollar returns are both low in the absence of a devaluation, high with a devaluation, enhancing the attractiveness of the dollar by making dollar contracts closer substitutes for output-based contingent contracts. $^{13}$

As in the case of macro dollarization, highly dollarized equilibria can dominate peso equilibria if there is a positive probability of collapse no matter how small. But, in the credit risk case, the lower the probability of a collapse, the broader the range of parameter values for which a fully dollarized equilibrium exists. Indeed, as fear of floating becomes extreme, the need for an overvaluation overhang vanishes $(\widehat{\delta} \rightarrow 0 \text { as } \bar{\delta} \rightarrow \tilde{\delta}+\delta)^{14}$

This also enhances the scope for overall contractionary devaluations (such that $\varpi>\mu \widehat{\delta}$ ). Indeed, in the limit case of extreme fear of floating, a vanishing overvaluation overhang, and positive liquidation costs (no matter how small), devaluations are always contractionary

${ }^{13}$ Contingent contracts that fully tie the returns on the loan to that of the project would of course dominate dollar contracts if they were available.

14 That agents can prefer the dollar to the MVP (i.e., a fully credible peso) under high fear of floating is the basic result in Jeanne's (2002). 
(relative to the initial equilibrium) when the economy is highly dollarized. In turn, the predominance of contractionary devaluations should now induce a negative correlation between investors' non financial incomes and the exchange rate. Thus, in an already highly dollarized environment with fragile balance sheets, the safe haven effect can further promote the use of the dollar.

Finally, notice that since $\delta^{R}(v)>\delta^{R}(0)$, the range of parameter values for which the dollar is preferred to the peso is broader than that for which the dollar is preferred to the MVP. The relative peso's attractiveness is undermined by its low credibility, which raises its nominal cost and increases the interest rate risk of peso contracts. ${ }^{15}$

\section{Equilibria under an endogenous monetary policy}

Consider now instead the opposite case where $b$ is large. In this case, the endogeneity of monetary policy can give rise to multiple equilibria. The reasons underlying the multiplicity of equilibria are clear. A fully dollarized economy enhances fear of floating, limiting the currency risk associated with dollar loans but increasing the interest rate risk of MVP (and peso) loans. Inversely, a peso economy limits fear of floating, eliminating the interest rate risk of peso loans while boosting the currency risk of dollar loans. However, as in the case of an exogenous monetary policy, the dollar can only dominate the MVP if overvaluations are contractionary and there is an overvaluation overhang. ${ }^{16}$

\section{Alternative Paradigms}

\section{A. Imperfect Information}

Consider now the case where information is imperfect and there are multiple creditor banks. Going to the extreme, suppose that banks cannot observe the currency exposure of the debtor. In this case, creditors behave strategically and coordination failures generate inferior equilibria.

Proposition 3. When debtors' currency exposure is not observable, only corner solutions (full dollarization or full pesification) are stable equilibria. ${ }^{17}$

\footnotetext{
15 That agents prefer the dollar to the peso under low monetary credibility is reminiscent of Calvo and Guidotti's (1989) finding in the context of public debt that the viability of nominal contracting in local currency shrinks drastically under expectations of severe inflation. The result extends here to the case of private contracts.

16 The conditions for dollar dominance are the same as in the case of an exogenous devaluation trigger (the proof in Appendix II extends to the limit case in which $\bar{\delta}(1)=\delta^{R}(1)$ ).

${ }^{17}$ The conclusion that the dollar dominates the peso in an environment of imperfect markets
} 


\section{Proof. See Appendix I}

With imperfect information, the marginal creditor bank cannot be sure of choosing the same currency mix as other creditors. Thus, the loan recovery value of his marginal loan becomes a function of his marginal currency mix relative to that of other creditors. When a devaluation triggers a default, dollar claims benefit at the expense of peso claims. Should the economy be heavily dollarized, the presumption should be that debtors borrow in dollars. Hence, no creditor should have any incentive to lend in pesos.

\section{B. Moral Hazard}

Consider finally the case where banks may also become bankrupt. In this case, the deposit guarantee introduces moral hazard and creates a further bias towards corner equilibria.

Proposition 4. With fully guaranteed deposits, no bank capital, and an exogenous monetary policy, perverse corner equilibria can obtain in which the "riskiest" currency dominates: full dollarization if currency risk dominates, full pesification in the opposite case. With an endogenous monetary policy, there may be situations in which no stable equilibria exist. Proof. See Appendix III

When deposits are insured, banks do not fully internalize credit risk. Instead, unless they have enough to lose in the event of default (i.e., enough capital at risk), they intermediate in the currency that maximizes the option value of the implicit guarantee. ${ }^{18}$ As the value of an option depends positively on the volatility of the underlying asset, the holder of the option maximizes the risk associated with it.

\section{De-Dollarization}

\section{A. Strengthening Monetary Credibility}

Let us now examine whether a return to peso intermediation is possible once the economy is dollarized. In the case of an MVP equilibrium (whether it results from price risk or credit risk), the culprit in either case is the lack of monetary credibility. De-dollarization should thus be the mirror image of dollarization. A gradually improving credibility should, paripassu, de-dollarize the MVP portfolio, and eventually (as $v \rightarrow 0$ ) bring the economy back to a peso equilibrium.

follows results first obtained by Chamon (2001) and Aghion, Bacchetta and Banerjee (2001). The conclusion is made symmetric here (the peso can also dominate the dollar) by extending the analysis to incorporate interest rate risk.

${ }^{18}$ This result was first obtained by Burnside, Eichenbaum, and Rebelo (2001). It is consistent with Broda and Levy Yeyati (2003), who find that, with currency blind risk premia, deposit insurance contributes to dollarization. 
As long as monetary policy is exogenous to dollarization, a broadly similar conclusion applies to the case in which the economy is no longer in the MVP equilibrium but is instead in a highly dollarized equilibrium. In this case, an improvement in monetary credibility should lower $\bar{\delta}$, eventually (if not immediately) altering the balance of risks in favor of the MVP. Thus, at some point, the economy should bounce back to the MVP equilibrium.

The case of an endogenous monetary policy is more complicated. The key difference with respect to the previous scenario is that once the economy is highly dollarized, the increased fear of floating (the jump from $\bar{\delta}(v)$ to $\bar{\delta}(1)$ ) makes a reversal to MVP impossible even if there is a large improvement in credibility. Indeed, the economy will remain highly dollarized as long as:

$$
\tilde{\delta}+\widehat{\delta}-\delta^{R}(1, \bar{\delta}(1))<\delta^{R}(1, \bar{\delta}(1))-\delta^{R}(v, \bar{\delta}(1))
$$

Yet, neither $\delta^{R}(1, \bar{\delta}(1))$ nor $\delta^{R}(v, \bar{\delta}(1))$ are functions of $v$ (check (15) and (17) for $\lambda_{i}=v$ ) Thus, the dollarization trap falls shut and the highly dollarized equilibria exhibit hysteresis.

Consider next the moral hazard case. A sufficient increase in capital requirements can induce banks to fully internalize risks, prompting them to switch out of dollar lending.

Proposition 5. With an endogenous monetary policy and when moral hazard is the only factor underlying dollarization, there is a range of capital values, such that $\left.k \in\left[R_{D}^{*}+\frac{\bar{\delta}(v)+\widehat{\delta}+\tilde{\delta}}{2}-\hat{\rho}, R_{D}^{*}+\frac{\bar{\delta}(1)+\widehat{\delta}+\tilde{\delta}}{2}\right)-\hat{\rho}\right]$ for which multiple equilibria (MVP or full dollarization) exist. Raising banks' capital above this range eliminates moral hazard, to the point where full dollarization is no longer a stable equilibrium.

Proof. See Appendix III

However, two important caveats apply. First, if dollarization also reflects pure default risk, eliminating moral hazard may be necessary to de-dollarize, but not sufficient. Second, if fear of floating is acute $((\bar{\delta}(1)+\bar{\delta}+\tilde{\delta}) / 2 \rightarrow \bar{\delta}+\tilde{\delta})$, the required increase in capital requirements (although temporary if it succeeds in de-dollarizing the economy) that would eliminate moral hazard could exceed the usually accepted prudential norms for risk tolerance (an event of an exceptionally large magnitude whose probability is excessively remote). Indeed, with high risk aversion and/or imperfect capital markets, capital can have a high opportunity cost. If so, an increase in capital requirements could result in higher bank spreads and lead to financial disintermediation or alternative, perhaps more risky, forms of intermediation. ${ }^{19}$

${ }^{19}$ Instead, introducing high capital requirements on dollar loans in a non-dollarized economy has no cost. 
Consider finally the case of imperfect information. In this case, improvements in monetary credibility are unlikely to have any effect. As long as there exists a range of shocks that induce both a devaluation and a default, and other banks lend in dollars, denominating loans in dollars remains the best "defensive option" against the risk that claims will become diluted during the process of liquidation. Thus, even when peso loans would clearly be less risky if all creditors would lend in pesos, the economy remains fully dollarized.

\section{B. Moving Towards a More Flexible Exchange Rate Regime}

Is a move towards a float (the "just do it" solution) likely to be more effective than building up monetary credibility through gradual institutional reforms? In the pure price risk paradigm, increasing the flexibility of the exchange rate regime (lowering $\bar{\delta}$ ) can only help de-dollarize if it raises the volatility of the exchange rate relative to the volatility of inflation, thereby raising the risk of dollar investments relative to peso investments. However, such a switch will not help if credibility remains an issue and the volatility of expected inflation rises, pari passu, with that of the exchange rate (in terms of the model, lowering $\bar{\delta}$ will only help if it leads to a lower $v$ ). Floating could enhance credibility if it gives the monetary authority a better opportunity to "prove itself"; however, this is by no means a done deal.

In the perfect information credit risk paradigm, a full float eliminates interest rate risk while maintaining currency risk in the high dollarization region. Thus, it clearly allows the MVP to prevail over the dollar. Moreover, even though the peso may continue to pay a premium (if $v>0$ ), it is also credit risk-free, and hence, is a (weakly stable) equilibrium. A float can thus also allow the peso to dominate the dollar even when it lacks credibility.

This last conclusion is subject to two important caveats, however. First, it does not hold with risk aversion. Highly dollarized mixes may continue to dominate the MVP if investors expect the correlation between corporate bankruptcies (hence aggregate output) and exchange rate depreciations to persist. Moreover, even without safe haven effects, the MVP will continue to dominate the peso as long as the latter is not fully credible. The conclusion above could also fail to hold due to time inconsistency. Should the monetary authority be unable to precommit, the economy may remain in a highly dollarized equilibrium where financial stress concerns will continue to dominate, preventing in practice a change of monetary regime.

A less demanding alternative is to follow a more symmetric monetary policy that allows the exchange rate to float upward, at least partly, in the event of an undervaluation. Indeed, by allowing the peso to reap valuation gains in the event of a real appreciation, such a policy reduces the ex ante cost of peso loans relative to the dollar. Admittedly, however, the more depreciations are delayed (the more fear of floating), the less scope there is for the exchange rate to appreciate.

A flexible exchange rate policy (such as crawl) that systematically corrects for potential overvaluations might also help dislodge the economy from its high dollarization equilibrium. 
However, in addition to lowering (or eliminating) $\widehat{\delta}$, such a policy may also reduce the expected probability of a large exchange rate adjustment, thereby reducing $\widehat{\delta}+\tilde{\delta}-\bar{\delta}$. The effectiveness of this policy will therefore depend on which effect dominates at the limit in the minds of the public.

Consider finally the cases of moral hazard and imperfect information. In the case of moral hazard, reducing $\bar{\delta}$ can help de-dollarization by increasing the range of shocks that may lead to corporate bankruptcies, thereby increasing banks' exposure to risk. In contrast, in the case of imperfect information, enhancing the flexibility of the exchange rate may have a perverse effect if it increases the expected correlation between exchange rate fluctuations and corporate bankruptcies. $^{20}$

\section{CONCLUSIONS}

This paper presented a unified framework to help analyze the roots of financial dollarization and address its risks. It showed that domestic financial equilibria may gravitate around interior MVP solutions or shift towards corner (dollar or peso) solutions. Forces supporting the interior MVP allocation arise from both the supply side and the demand side of the loanable funds market. The MVP minimizes borrowers' exposure to credit risk by limiting their balance sheet mismatch. At the same time, it limits lenders' direct exposure to currency risk by providing a fully hedged portfolio. Liquidation costs and risk aversion magnify these effects.

However, the MVP portfolio increasingly approximates the dollar as the credibility of monetary policy declines. Combined with policy endogeneity (which minimizes the risk associated with dollar loans), asymmetry (which turns dollar loans into one-sided bets), and the existence of an overvaluation overhang (which further raises expected returns on dollar loans in the event of a large depreciation), the low credibility of monetary policy can boost the dollar to the point where highly (or fully) dollarized mixes become stable equilibria. While such equilibria are inferior to MVP equilibria, a shift from a highly dollarized equilibrium to MVP becomes problematic once the economy becomes highly dollarized (there is dollarization hysteresis).

Moral hazard and market imperfections further push towards full corner solutions. Official guarantees (reflecting, as in the case of monetary policy endogeneity, policymakers' concerns for financial stress and inability to precommit) boost the dollar (peso) in an economy that is already dollarized (pesoized), hence exposed to currency-induced credit risk (interest rateinduced credit risk). Market frictions (imperfect information and costly contracting) similarly favor the dollar (peso) by preventing coordination between multiple creditors. When

\footnotetext{
${ }^{20}$ Paradoxically, the only case in which the dollar would lose its edge over the peso in a dollarized economy would be if fear of floating becomes so extreme that devaluations are ruled out under any circumstance, in which case currency denomination becomes irrelevant.
} 
bankruptcy proceeds are allocated proportionally among all creditors at the exchange rate (real interest rates) prevailing at the time of the bankruptcy, it is individually optimal (but socially suboptimal) for a marginal creditor to denominate his loan in dollars (pesos).

Policy implications towards de-dollarization depend on the underlying roots of dollarization and whether it reflects an MVP equilibrium or an alternative highly (or fully) dollarized equilibrium. In the former case (which is more likely in economies with moderate and stable dollarization), policy should concentrate on enhancing the credibility of monetary policy through institutional reform and capacity building. By clarifying policy preferences, the introduction of an inflation targeting-type regime should help. Floating, or at least increasing the flexibility of the exchange rate, can also help by providing better opportunities for the central bank to demonstrate its managing skills, thereby building up its credibility.

Policy options are less straightforward for highly dollarized equilibria or where dollarization is increasing rapidly (reflecting the transition from an interior to a corner solution).

Improving monetary credibility may not be sufficient to dislodge the economy from its high dollarization equilibrium (or reverse dollarization dynamics). Moreover, switching the monetary regime is difficult when financial stability concerns overwhelm monetary policy. In addition, monetary policy shifts are unlikely to have much effect and might even be counterproductive when dollarization reflects coordination failures between market participants.

In such extreme cases, policies that might help de-dollarization include: (i) institutional reforms that aim at reducing bankruptcy costs (thereby reducing fear of floating); (ii) the promotion of price-indexed instruments that constitute a better immediate substitute to the dollar and provide a mid-way station towards the peso; ${ }^{21}$ and (iii) administrative measures to directly reduce (or eliminate) dollarization. By allowing for a discrete change in monetary policy and a coordinated move by all borrowers from dollar borrowing to peso borrowing, the latter may help speed up the de-dollarization process (thereby limiting transition costs). However, this requires a sufficient concomitant improvement in credibility to ensure that the peso equilibrium is stable. The economy will otherwise re-dollarize or disintermediate.

\footnotetext{
${ }^{21}$ Unlike the MVP, price-indexed instruments do not require multiple currency contracting, and fully protect contracts against all inflationary surprises. Nonetheless, price-indexed markets may not take off by themselves and may require substantial and sustained promotional efforts. See Herrera and Valdes (2004).
} 


\section{FINANCIAL DOLLARIZATION EQUILIBRIA}

\section{A. General Formulation}

Investors trade off risk and returns over their total income $Y=\bar{Y}+r^{d}$, where $\bar{Y}$ is their nonfinancial income (which does not depend on $\lambda_{i}$ ), such that:

$$
\operatorname{Max}\left[E\left\{r^{d}\right\}-\frac{C}{2} \operatorname{Var}\{Y\}\right]
$$

Defining $N D^{j}, D^{j}, j=B, C$ as the no-default and default outcomes for banks and corporates, respectively, banks' maximization problem may be written:

$$
\operatorname{Max}\left[E\left\{\left(r^{l}-r^{d}\right) / N D^{C}\right\}+E\left\{\left(\rho-\varpi-r^{d}\right) / D^{C}, N D^{B}\right\}-E\left\{k / D^{B}\right\}\right]
$$

Finally, corporates’ maximization problem is such that:

$$
\operatorname{Max}\left[E\left\{\left(\rho-r^{l}\right) / N D^{C}\right\}\right]
$$

Summing up these three maximization expressions and noting that banks can only default if corporates do, so that $E\left\{\rho, r^{d}\right\}=E\left\{\rho, r^{d} / N D^{C}\right\}+E\left\{\rho, r^{d} / D^{C}, N D^{B}\right\}+E\left\{\rho, r^{d} / D^{B}\right\}$ and $E\left\{\varpi / D^{C}\right\}=E\left\{\varpi / D^{C}, N D^{B}\right\}+E\left\{\varpi / D^{B}\right\}$, leads to:

$$
\operatorname{Max}\left[E\{\rho\}-E\left\{\varpi / D^{C}\right\}-E\left\{\left(\rho+k-\varpi-r^{d}\right) / D^{B}\right\}-\frac{C}{2} \operatorname{Var}\{Y\}\right]
$$

Since $E\{\rho\}$ is independent of $\lambda_{i}$, maximizing this last expression is equivalent to:

$$
\operatorname{Min}\left[E\left\{\varpi / D^{C}\right\}+E\left\{\left(\rho+k-\varpi-r^{d}\right) / D^{B}\right\}+\frac{c}{2} \operatorname{Var}\{Y\}\right]
$$

The first term in this expression is the credit risk term (currencies that minimize credit risk are preferred). The second term is a moral hazard term and corresponds to the option value of defaulting. The preferred currency is that which maximizes available net subsidies as derived from the net payments by the deposit guarantor in the event of bank default (the deposit rate, 
including valuation gains, minus the recovery value of the loans). ${ }^{22}$ The third term is the risk aversion term. The preferred currency is that which better smoothes out investors' income. Let us now explore how this general expression is affected under three special cases.

\section{B. Risk Aversion and No Credit Risk}

Consider first the case in which neither corporates nor banks default. Expressing real interest rates as $r=R+\lambda_{i} S-P$ where $S$ is the nominal exchange rate and $P$ the price level, (A-5) reduces to:

$$
\operatorname{Min}[\operatorname{Var}\{Y\}]=\operatorname{Min}\left[\operatorname{Var}\left\{\bar{Y}+R^{d}\right\}+\lambda_{i}^{2} \operatorname{Var}\{S\}+\operatorname{Var}\{P\}-2 \lambda_{i}(\operatorname{Cov}\{S, P\}-\operatorname{Cov}\{S, \bar{Y}\})\right]
$$

Differentiating with respect to $\lambda_{l}$ :

$$
\lambda_{i}=\frac{\operatorname{Cov}\{S, P\}}{\operatorname{Var}\{S\}}-\frac{\operatorname{Cov}\{S, \bar{Y}\}}{\operatorname{Var}\{S\}}
$$

The first term is the MVP term. The second term is the "safe haven" effect.

\section{Credit risk, No Risk Aversion, and No Bank Default}

Consider now instead the extreme opposite case where corporates (but not banks) may default and there is no risk aversion $(c=0)$. In this case, $(\mathrm{A}-5)$ reduces to:

$$
\operatorname{Min}\left[E\left\{\varpi / D^{C}\right\}\right]
$$

If banks are single creditors, $\varpi$ is independent of $\lambda_{i}$, and this further reduces to choosing $\lambda_{i}$ that minimizes the probability of corporate default, $E\left\{D^{C}\right\}$. Take now the case of multiple creditors. With perfect information and costless recontracting, any deviation by marginal creditors from the composition chosen by other creditors should lead to an immediate repricing of all loans as soon as it alters the risk profile of the debtor. Thus, the borrower should fully internalize credit risk and resist any switch in the mix that increases credit risk, leading to the same equilibria as in the single creditor case.

\footnotetext{
${ }^{22}$ Notice that banks do not internalize the liquidation costs (both from corporates and from banks) that occur when they default. Thus, eliminating moral hazard is not equivalent to fully internalizing risks.
} 
With imperfect information, the resulting equilibria may be quite different. If the debtor's currency exposure is not observable and creditors are small, the currency choice made by an individual creditor has no measurable impact on the probability of default. Thus, $D^{C}$ is not $a$ function of $\lambda_{i}$. In contrast, $\varpi$ becomes a function of $\lambda_{i}$, as the loan recovery value of the marginal loan becomes a function of its currency mix relative to that of other creditors. When a devaluation triggers a default, payoffs to each creditor are proportional to his claims valued at the exchange rate prevailing at the time of liquidation. Thus, dollar claims benefit at the expense of peso claims. Inversely, when the default is induced by an overvaluation, peso contracts benefit over dollar contracts since they carry a higher nominal interest rate. Should the economy be heavily dollarized, the presumption should be that debtors borrow in dollars. Hence, no creditor should have any incentive to lend in pesos (the dollar equilibrium should be stable). By the same reasoning, the peso equilibrium should also be stable.

\section{Credit Risk, No Risk Aversion, and Bank Default}

Consider finally the case where both corporates and banks may default, but there is perfect information. In the absence of bank capital, banks default together with the corporates; hence $E\left\{D^{C}, N D^{B}\right\}=0$ and (A-5) may be re-written as:

$$
\operatorname{Max}\left[E\left\{\left(r^{d}-\rho\right) / D^{B}\right\}\right]
$$

The preferred currency is that which has the highest probability of default and the highest pay-offs to depositors in the event of default. Thus, the dollar is preferred when currency risk is high, the peso when interest rate risk is high. With an endogenous monetary policy, there could be no stable equilibria. Should banks intermediate in pesos, fear of floating would fall, making peso intermediation riskless. If so, peso intermediation could not be a stable equilibrium (the marginal bank would be better off intermediating in dollars). But, by a similar argument, dollar intermediation might not be stable either: if the interest rate risk of peso loans exceeds the currency risk of dollar loans and the peso lacks credibility (raising peso nominal interest rates), the marginal bank could be better off switching to pesos.

\section{Default Equilibria AND MONETARY CREDIBILITY}

\section{A. Peso and MVP Equilibria}

Setting $\bar{\delta}=\bar{\delta}_{v}=a v / \mu$ in (15), defining $Y=\bar{\delta} / \tilde{\delta}-\delta^{R} / \tilde{\delta}$, and picking the root $Y \in[0,1]$ leads to the following expression:

$$
Y=1+(\varpi / \mu \tilde{\delta})-\left[(1+(\varpi / \mu \tilde{\delta}))^{2}+2 \frac{d / \tilde{\delta}-a v}{\mu}+2 \frac{\lambda_{i}-v}{1-v} \frac{\Delta}{\mu \tilde{\delta}}\right]^{\frac{1}{2}}
$$


For the peso equilibrium $\left(\lambda_{i}=0\right)$, it can be immediately checked that $\partial Y / \partial v>0$ and $Y$ goes from negative to positive as $v$ rises from zero to one. Thus, the peso equilibrium is riskless if credibility is high but becomes risky as credibility declines. On the other hand, since high dollar mixes are exposed to currency risk, they are clearly dominated by high peso mixes.

Since $\partial Y / \partial \lambda_{i}<0$, any shift into a more dollarized mix would continue to be riskless as long as $\lambda_{i} \leq v$ (it does not induce currency risky). However, no marginal shift towards the peso could occur as such a shift would face an immediate increase in interest rate risk, reflecting the positive slope of the $\delta^{R}$ schedule. Thus, the peso equilibrium is weakly stable as long as it is riskless. However, once the peso becomes risky, a shift into a more dollarized mix, that ensures $\bar{\delta}=\delta^{R}$, becomes preferable. At that point, $\lambda$ is obtained by setting $Y=0$ in (A-4), as:

$$
\lambda=v+(1-v) \frac{a v \tilde{\delta}-d}{\Delta}
$$

Thus, provided $d / \tilde{\delta}<a$, dollarization eventually reaches the MVP region. Once there, a small shift towards the dollar faces increased interest rate risk but no currency risk. However, a larger shift eventually faces a large increase in currency risk. Therefore, there must be a mix, slightly above MVP, that is fully stable.

\section{B. Dollar Equilibria}

There can only be a jump from the MVP equilibrium to the highly dollarized equilibrium if the sum of interest rate and credit risk in the dollar region is less than the interest rate risk in the MVP region:

$$
\tilde{\delta}+\bar{\delta}-\operatorname{Min}\left\{\bar{\delta}_{v}, \delta^{R}(1)\right\}<\bar{\delta}_{v}-\delta^{R}(v)
$$

Consider the more general case where $\delta^{R}(1)<\bar{\delta}_{v}$ and define $X=\left(\tilde{\delta}+\widehat{\delta}-\delta^{R}(1)\right) / \tilde{\delta}$. Subtract (15), expressed for $\lambda_{i}=v$, from (17). After some rearrangements, this can be written as:

$$
(Y-X)[1-(\varpi / \mu \tilde{\delta})-(X+Y) / 2]-[(\tilde{\delta}+\widehat{\delta}-\bar{\delta}) / \tilde{\delta}][\widehat{\delta} / \tilde{\delta}-(\tilde{\delta}+\widehat{\delta}-\bar{\delta}) / 2 \tilde{\delta}]=0
$$

It immediately follows that Y-X>0 if $\tilde{\delta}>(\tilde{\delta}+\bar{\delta}-\bar{\delta}) / 2>0$ and $\varpi / \mu \tilde{\delta}<1-(X+Y) / 2$; this last condition can be written: 


$$
\varpi / \mu \tilde{\delta}<(\tilde{\delta}+\bar{\delta}-\bar{\delta}) / 2 \tilde{\delta}+\left(\delta^{R}(v)-\widehat{\delta}\right) / 2 \tilde{\delta}+\left(\delta^{R}(1)-\widehat{\delta}\right) / 2 \tilde{\delta}
$$

For $\bar{\delta}, \delta^{R}(v), \delta^{R}(1) \in[\widehat{\delta}, \tilde{\delta}+\widehat{\delta}], \mu>0$, this defines a positive upper bound for $\varpi$. In addition, the condition $\delta^{R}(1) / \bar{\delta}<1$ must also hold, which, with (17), leads to:

$$
\mu \frac{\bar{\delta}^{2}-\widehat{\delta}^{2}}{2 \tilde{\delta}}<d<\mu \frac{\bar{\delta}^{2}-\widehat{\delta} \bar{\delta}}{\tilde{\delta}+\widehat{\delta}-\bar{\delta}}
$$

It can be immediately checked that for $\bar{\delta} \in[\widehat{\delta}, \tilde{\delta}+\widehat{\delta}]$ this range is non-empty; moreover its upper bound vanishes as $\bar{\delta} \rightarrow \tilde{\delta}+\widehat{\delta}$. It is also easy to check with (12) that the condition $\delta^{X}(1)<\bar{\delta}$ is satisfied if (A-8) is satisfied and $\mu<1$.

\section{Moral HAZARD EqUILIBria}

Suppose the economy is intermediating in dollars. If the devaluation trigger is above the bank default trigger, bank defaults coincide with corporate defaults and (A-6) reduces to:

$$
\operatorname{Min}\left[E\left\{\left(\rho+k-r^{d}\right) / D^{B}\right\}\right]
$$

If MVP lending is risk free, banks do not default when they intermediate in MVPs, and the expression above equals zero for the MVP. Hence, the dollar is preferred if:

$$
E\left\{\left(\rho+k-r^{d}\right) / D^{B}\right\}<0
$$

which is the case if:

$$
k<R_{D}^{*}+\frac{\bar{\delta}(1)+\widehat{\delta}+\tilde{\delta}}{2 \tilde{\delta}}-\widehat{\rho}
$$

Suppose, on the other hand, that the economy is intermediating in MVPs. Since MVP intermediation is risk free, banks will not switch to dollars if (A-9) is not satisfied, which, given the monetary policy associated with the MVP equilibrium, translates into:

$$
k>R_{D}^{*}+\frac{\bar{\delta}(v)+\widehat{\delta}+\tilde{\delta}}{2 \tilde{\delta}}-\widehat{\rho}
$$




\section{REFERENCES}

Aghion, P., P. Bacchetta, and A. Banerjee, 2001, “A Corporate Balance-Sheet Approach to Currency Crises” Working Paper No. 01.05 (Gerzensee: Swiss National Bank).

Broda, C., and E. Levy Yeyati, 2003, “Endogenous Deposit Dollarization,” Federal Reserve Bank of New York Staff Papers, No. 160.

Burnside, C., M. Eichenbaum, and S. Rebelo, 2001, "Hedging and Financial Fragility in Fixed Exchange Rate Regimes,” European Economic Review, Vol. 45, pp 1151-93

Calvo, G., and P. Guidotti, 1989, “Credibility and Nominal Debt: Exploring the Role of Maturity in Managing Inflation,” IMF Staff Papers, Vol. 37 (Sept), pp. 612-35. , and C. Reinhart, 2002, “Fear of Floating,” Quarterly Journal of Economics, Vol. 117, No. 2, pp. 379-408.

Chamon, M., 2001, "Foreign Currency Denomination of Foreign Currency Debt: Has the Original Sin Been Forgiven but not Forgotten?” (unpublished; Cambridge: Harvard University).

De Nicolo, G., P. Honohan, and A. Ize, 2005, “Dollarization of Bank Deposits: Causes and Consequences,” Journal of Banking and Finance, Vol. 29, No. 7, pp. 1697-1727.

Galindo, A., U. Panizza, and F. Schiantarelli, 2003, "Debt Composition and Balance Sheet Effects of Currency Depreciation: A Summary of the Micro Evidence,” Emerging Markets Review, Vol. 4, Issue 4, pp. 330-339

Herrera, L.O., and R. Valdes, 2003, "Dedollarization, Indexation and Nominalization: The Chilean Experience,” (Unpublished; Santiago: Central Bank of Chile).

Ize, A., and E. Levy Yeyati, 2003, “Financial Dollarization,” Journal of International Economics, Vol. 59, pp. 323-347. , and A. Powell, 2004, "Prudential Responses to De Facto Dollarization,” IMF Working Paper 04/66 (Washington: International Monetary Fund).

Jeanne, O., 2002, “Why Do Emerging Economies Borrow in Foreign Currency.” 